\title{
A novel GATA4 loss-of-function mutation responsible for familial dilated cardiomyopathy
}

\author{
LAN ZHAO $^{1^{*}}$, JIA-HONG XU ${ }^{2 *}$, WEN-JUN XU ${ }^{2}$, HONG YU $^{2}$, QIAN WANG ${ }^{3-5}$, HONG-ZHEN ZHENG ${ }^{3-5}$, \\ WEI-FENG JIANG ${ }^{3}$, JIN-FA JIANG ${ }^{2}$ and YI-QING YANG ${ }^{3-5}$
}

\author{
${ }^{1}$ Department of Cardiology, Yantaishan Hospital, Yantai, Shandong 264001; ${ }^{2}$ Department of Cardiology, Tongji Hospital, \\ Tongji University School of Medicine, Shanghai 200065; ${ }^{3}$ Department of Cardiology, ${ }^{4}$ Cardiovascular Research Laboratory \\ and ${ }^{5}$ Central Laboratory, Shanghai Chest Hospital, Shanghai Jiao Tong University, Shanghai 200030, P.R. China
}

Received October 6, 2013; Accepted December 20, 2013

DOI: $10.3892 /$ ijmm.2013.1600

\begin{abstract}
Dilated cardiomyopathy (DCM) is the most common form of primary myocardial disorder and is associated with substantial morbidity and mortality. Increasing evidence suggests that genetic risk factors play an important role in the pathogenesis of idiopathic DCM. However, DCM is a genetically heterogeneous disease, and the genetic defects responsible for DCM in an overwhelming majority of cases remain to be identified. In the present study, the entire coding region and the splice junction sites of the GATA4 gene, which encodes a cardiac transcription factor essential for cardiogenesis, were sequenced in 150 unrelated patients with idiopathic DCM. The available relatives of the index patient harboring an identified mutation and 200 unrelated ethnically matched healthy individuals used as controls were genotyped. The functional characteristics of the mutant GATA4 were delineated in contrast to its wild-type counterpart using a luciferase reporter assay system. As a result, a novel heterozygous GATA4 mutation, p.V291L, was identified in a family with DCM inherited in an autosomal dominant pattern, which co-segregated with DCM in the family with complete penetrance. The missense mutation was absent in 400 control chromosomes, and the altered amino acid was completely conserved evolutionarily among species. Functional analysis revealed that the GATA4 mutant was associated with significantly diminished
\end{abstract}

Correspondence to: Dr Jin-Fa Jiang, Department of Cardiology, Tongji Hospital, Tongji University School of Medicine, 389 Xincun Road, Shanghai 200065, P.R. China

E-mail: jinfajiang@sina.cn

Dr Yi-Qing Yang, Department of Cardiology, Shanghai Chest Hospital, Shanghai Jiao Tong University, 241 West Huaihai Road, Shanghai 200030, P.R. China

E-mail: yang99yang66@hotmail.com

${ }^{*}$ Contributed equally

Key words: dilated cardiomyopathy, genetics, transcription factor, GATA4, reporter gene transcriptional activity. The findings expand the mutational spectrum of GATA4 linked to DCM and provide novel insight into the molecular etiology involved in DCM, suggesting the potential implications in the early prophylaxis and allelespecific treatment for this common type of cardiomyopathy.

\section{Introduction}

Dilated cardiomyopathy (DCM) is the most common form of primary heart muscle disease characterized by dilation and systolic dysfunction of the left or both ventricles with normal ventricular wall thickness, in the absence of underlying conditions such as coronary artery disease, hypertension and valvular anomalies (1). It is the most frequent cause of congestive heart failure and sudden cardiac death in the young and is the most common indication for cardiac transplantation in both child and adult patients worldwide $(1,2)$. DCM may occur as a result of acquired factors, including infectious agents, toxins, nutritional deficiencies and autoimmune disorders (1). However, in approximately $50 \%$ of DCM cases, no acquired risk factors can be found, and such DCM is defined as idiopathic DCM, of which $25-50 \%$ are familial with at least two affected close relatives in each family, hence termed familial DCM (3). A growing body of evidence reveals a genetic origin in many patients with idiopathic DCM, and a long list of mutations in more than 50 genes has been associated with familial DCM (3). However, these established DCM-associated genes only account for roughly one-third of cases, and each gene has a low mutational frequency, with most occurring in less than $1 \%$ of patients with DCM (4). Therefore, continued genetic studies in other cohorts of DCM patients are necessary in order to gain novel insight into the molecular basis for HCM.

The zinc finger-containing transcription factor GATA4 is abundantly expressed in the heart at various developmental stages and continues to be highly expressed in adult cardiomyocytes, where it mediates the expression of several crucial structural and regulatory genes, including those encoding atrial natriuretic factor (ANF), brain natriuretic factor, carnitine palmitoyltransferase $\mathrm{I} \beta$, troponin I, troponin $\mathrm{C}, \alpha$ - and $\beta$-myosin heavy chain (5-7). In humans, a great number of mutations in the GATA4 gene have been implicated in a wide variety of congenital cardiovascular malformations, including 
atrial septal defect, ventricular septal defect, tetralogy of Fallot, endocardial cushion defect, patent ductus arteriosus, pulmonary stenosis and hypoplastic right ventricle (8-16), highlighting the pivotal role of GATA4 in human cardiogenesis. Recently, a novel GATA4 mutation was reported to underlie familial DCM (17). In mice, GATA4 has been substantiated to be essential for proper cardiovascular morphogenesis, and homozygous GATA4 deletion causes early embryonic lethality due to abnormal embryogenesis and failure to form heart tube $(18,19)$. Mice expressing $70 \%$ less GATA4 protein died between day 13.5 and 16.5 of gestation, and common atrioventricular canal, double outlet right ventricle and hypoplastic ventricular myocardium were observed in these embryos (20). Moreover, transgenic mice expressing GATA4 mutants suffered from various cardiac deformations, including septal defects, right ventricular hypoplasia, endocardial cushion defect, tetralogy of Fallot, double outlets of the right ventricle and cardiomyopathy, similar to abnormalities occurring in humans (9). More importantly, mice with cardiac-specific deletion of GATA4 survived into adulthood but showed progressive cardiac enlargement and functional impairment with increased rates of cardiomyocyte apoptosis that was positively correlated to GATA4 levels (21). These results demonstrate that GATA4 plays a key role in maintaining physiological homeostatic remodeling in adult hearts by promoting cell survival and regeneration and inhibiting programmed cell death (22-26).

GATA4 regulates downstream gene expression by forming complexes with other transcriptional factors, including NKX2-5 and TBX5 (7). NKX2-5 is another regulator required for normal cardiac development and its expression and functions overlap with those of GATA4 during embryogenesis (12). Furthermore, GATA4 and NKX2-5 have been shown to physically interact and synergistically regulate the expression of multiple important cardiac target genes, including those coding for ANF, T- and L-type $\mathrm{Ca}^{2+}$ channels, connexin40, $\alpha$-actin, ID2 and LRRC10 (7). In mice, targeted disruption of NKX2-5 led to impaired cardiac growth and chamber formation, deranged gene regulatory network, and early embryonic death, while cardiac-specific knockout of NKX2-5 resulted in progressive cardiomyopathy and complete heart block (27-29). In humans, mutations in the NKX2-5 gene have been linked to diverse congenital heart diseases, including cardiac septal defects, tetralogy of Fallot, transposition of the great arteries, hypoplastic left heart, valvular deformities and left ventricular contractile dysfunction (30-32), and adult-onset DCM (33). These data suggest that GATA4 is an alternative candidate gene for DCM.

\section{Materials and methods}

Patients and controls. A cohort of 150 unrelated patients with idiopathic DCM was recruited from the Han Chinese population. The available relatives of the index patients were also enlisted. A total of 200 ethnically matched unrelated healthy individuals were enrolled as controls. All participants were evaluated by detailed medical history, physical examination, chest radiography, electrocardiogram, echocardiography and exercise performance testing. Cardiac catheterization, angiography, endomyocardial biopsy and cardiac magnetic resonance imaging were performed only if there was a strong clinical indication. Medical records were also reviewed in the case of deceased or unavailable relatives. Diagnosis of idiopathic DCM was made in accordance with the criteria established by the World Health Organization/International Society and Federation of Cardiology Task Force on the Classification of Cardiomyopathy: a left ventricular end-diastolic diameter $>27 \mathrm{~mm} / \mathrm{m}^{2}$ and an ejection fraction $<40 \%$ or fractional shortening $<25 \%$ in the absence of abnormal loading conditions, coronary artery disease, congenital heart lesions, and other systemic diseases $(17,34)$. Individuals were excluded if they had insufficient echocardiographic image quality, or coexistent conditions that may lead to contractile dysfunction, such as uncontrolled systemic hypertension, coronary artery disease or valvular heart disease. Familial DCM was defined as having two or more first-degree relatives with idiopathic DCM. Peripheral venous blood samples from all the participants were prepared. The clinical studies were performed with investigators blinded to the results of the genotypes. This study conformed to the principles of the Declaration of Helsinki, and the study protocol was approved by the local institutional ethics committee. Written informed consent was obtained from all participants prior to the study.

Genotyping. Genomic DNA was extracted from blood samples obtained from all participants with the Wizard Genomic DNA purification kit (Promega, Madison, WI, USA). The coding exons and exon-intron boundaries of the GATA4 gene were sequenced in 150 unrelated patients with idiopathic DCM. When a mutation was found in an index patient, the available relatives of the mutation carrier and 200 unrelated healthy controls were genotyped for GATA4. The referential genomic DNA sequence of GATA4 was derived from GenBank (accession no. NC_000008). The primer pairs used to amplify the entire coding region and flanking splice junction sites of GATA4 by polymerase chain reaction (PCR) were designed as described previously (11). The PCR was conducted using HotStar Taq DNA polymerase (Qiagen, Hilden, Germany) on a PE 9700 thermal cycler (Applied Biosystems, Foster, CA, USA) with standard conditions and concentrations of reagents. Amplified products were purified with the QIAquick Gel Extraction kit (Qiagen). Both strands of each PCR product were sequenced with a BigDye ${ }^{\circledR}$ Terminator v3.1 Cycle Sequencing kit under an ABI PRISM 3130xl DNA analyzer (both from Applied Biosystems). DNA sequences were viewed and analyzed with the DNA Sequencing Analysis Software v5.1 (Applied Biosystems). The variant was validated by re-sequencing of an independent PCR-generated amplicon from the same subject. In addition, for an identified sequence variant, the single nucleotide polymorphism (SNP; http://www.ncbi.nlm.nih.gov/SNP) and human gene mutation (HGM; http://www.hgmd.org) databases were queried to confirm its novelty.

Alignment of multiple GATA4 protein sequences. Multiple GATA4 protein sequences among species were aligned using the online MUSCLE program, version 3.6 (http://www.ncbi. nlm.nih.gov/).

Prediction of the disease-causing potential of a GATA4 sequence variation. The causative potential of a GATA4 
Table I. Baseline clinical characteristics of the patients and controls.

\begin{tabular}{lccc}
\hline Parameters & $\begin{array}{c}\text { Patients } \\
(\mathrm{n}=150)\end{array}$ & $\begin{array}{c}\text { Controls } \\
(\mathrm{n}=200)\end{array}$ & P-value \\
\hline Mean age (years) & $45.6 \pm 12.5$ & $47.2 \pm 10.9$ & 0.2029 \\
Male, $\mathrm{n}(\%)$ & $82(54.7)$ & $111(55.5)$ & 0.8767 \\
Family history & $65(43.3)$ & $0(0)$ & $<0.0001$ \\
of DCM, n (\%) & & & \\
SBP $(\mathrm{mmHg})$ & $112.8 \pm 15.3$ & $120.0 \pm 13.6$ & 0.0001 \\
DBP $(\mathrm{mmHg})$ & $71.4 \pm 9.1$ & $82.5 \pm 8.6$ & $<0.0001$ \\
HR $(\mathrm{bpm})$ & $110.5 \pm 16.4$ & $78.3 \pm 10.7$ & $<0.0001$ \\
LVEDD $(\mathrm{mm})$ & $72.6 \pm 8.3$ & $47.9 \pm 6.0$ & $<0.0001$ \\
LVESD $(\mathrm{mm})$ & $59.5 \pm 9.8$ & $35.0 \pm 5.6$ & $<0.0001$ \\
LVEF $(\%)$ & $34.7 \pm 10.0$ & $65.2 \pm 7.4$ & $<0.0001$ \\
NYHA function class $(\%)$ & & & \\
I & $23(15.3)$ & NA & NA \\
II & $58(38.7)$ & NA & NA \\
III & $50(33.3)$ & NA & NA \\
IV & $19(12.7)$ & NA & NA \\
\hline
\end{tabular}

DCM, dilated cardiomyopathy; SBP, systolic blood pressure; DBP, diastolic blood pressure; HR, heart rate; LVEDD, left ventricular enddiastolic diameter; LVESD, left ventricular end-systolic diameter; LVEF, left ventricular ejection fraction; NYHA, New York Heart Association; NA, not applicable or not available.

sequence variation was predicted by MutationTaster (an online program at http://www.mutationtaster.org), which automatically provides a probability for the variation to be either a pathogenic mutation or a benign polymorphism. Of note, the P-value used here is the probability of the correct prediction rather than the probability of error as used in t-test statistics (i.e., a value close to 1 indicates a high accuracy of the prediction). Additionally, another online program PolyPhen-2 (http://genetics.bwh.harvard.edu/pph2) was also used to evaluate the pathogenic likeliness of a variation.

Expression plasmids and site-directed mutagenesis. The recombinant expression vector GATA4-pSSRa and the ANF-luciferase (ANF-luc) reporter plasmid, which contains the 2,600-bp 5'-flanking region of the $A N F$ gene, were kindly provided by Dr Ichiro Shiojima of the Chiba University School of Medicine, Japan. The identified mutation was introduced into the wild-type GATA4 using a QuickChange II XL Site-Directed Mutagenesis kit (Stratagene, La Jolla, CA, USA) with a complementary pair of primers. The mutant was sequenced to confirm the desired mutation and to exclude any other sequence variations.

Reporter gene assays. HeLa cells were cultured in Dulbecco's modified Eagle's medium (DMEM) supplemented with $10 \%$ fetal calf serum. The internal control reporter plasmid pGL4.75 (hRluc/CMV; Promega) was used in transient transfection analyses to evaluate the transcriptional activity of

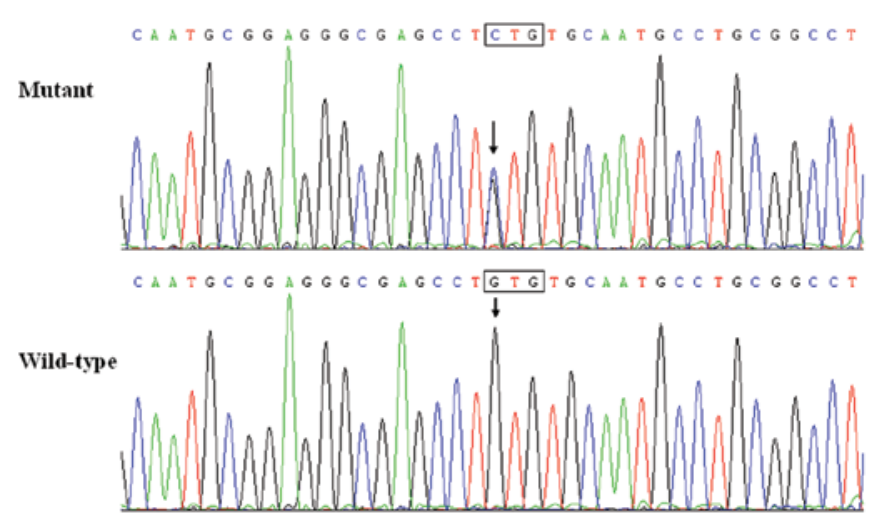

Figure 1. Sequence electropherograms showing the GATA4 variation compared with its control. The arrow indicates the heterozygous nucleotides of $\mathrm{G} / \mathrm{C}$ in the proband (mutant) or the homozygous nucleotides of $\mathrm{G} / \mathrm{G}$ in the corresponding control individual (wild-type). The rectangle denotes the nucleotides comprising a codon of GATA4.

the GATA4 mutant. HeLa cells were transfected with $0.4 \mu \mathrm{g}$ of wild-type or mutant GATA4-pSSRa, $1.0 \mu \mathrm{g}$ of ANF-luc, and $0.04 \mu \mathrm{g}$ of pGL4.75 using PolyFect transfection reagent (Qiagen). For co-transfection experiments, $0.2 \mu \mathrm{g}$ of wild-type GATA4-pSSRa, $0.2 \mu \mathrm{g}$ of mutant GATA4-pSSRa, $1.0 \mu \mathrm{g}$ of ANF-luc, and $0.04 \mu \mathrm{g}$ of pGL4.75 were used. Firefly luciferase and Renilla luciferase activities were measured with the Dual-Glo luciferase assay system (Promega) $48 \mathrm{~h}$ after transfection. The activity of the $A N F$ promoter was presented as fold activation of firefly luciferase relative to Renilla luciferase. Three independent experiments were performed at minimum for wild-type and mutant GATA4.

Statistical analysis. Data are expressed as means \pm standard deviation (SD). Continuous variables were tested for normality of distribution, and the Student's unpaired t-test was used for comparison of numeric variables between two groups. Comparison of the categorical variables between two groups was performed using Pearson's $\chi^{2}$ test or Fisher's exact test when appropriate. A two-tailed P-value of $<0.05$ indicated statistical significance.

\section{Results}

Clinical characteristics of the study subjects. A total of 150 unrelated patients with idiopathic DCM were clinically evaluated in contrast to 200 control individuals. None had apparent traditional risk factors for DCM. All of the patients manifested with a typical DCM phenotype as described previously (34). The control individuals had no evidence of structural cardiac diseases, and their echocardiogram results were normal. The baseline clinical characteristics of the study subjects are summarized in Table I.

GATA4 mutation. By direct sequencing of the GATA4 gene, a heterozygous mutation was identified in 1 out of 150 unrelated patients with idiopathic DCM, with a mutational prevalence of $\sim 0.67 \%$. Specifically, a substitution of $\mathrm{C}$ for $\mathrm{G}$ in the first nucleotide of codon 291 (c. $871 \mathrm{G}>C$ ), predicting the transition 
Table II. Phenotypic characteristics and status of the GATA4 mutation in the affected living pedigree members.

\begin{tabular}{lcclcccr}
\hline Individual & Gender & $\begin{array}{c}\text { Age } \\
\text { (years })\end{array}$ & $\begin{array}{c}\text { Cardiac } \\
\text { phenotype }\end{array}$ & $\begin{array}{c}\text { LVEDD } \\
(\mathrm{mm})\end{array}$ & $\begin{array}{c}\text { LVESD } \\
(\mathrm{mm})\end{array}$ & $\begin{array}{c}\text { LVEF } \\
(\%)\end{array}$ & $\begin{array}{c}\text { ECG } \\
\text { findings }\end{array}$ \\
\hline III-1 & M & 53 & DCM, ASD & 75 & 68 & 32 & PAF, AVB, RBBB \\
III-6 & F & 46 & DCM & 82 & 71 & 27 & $+/-$ \\
IV-1 & F & 27 & DCM & 60 & 52 & 39 & $+/-$ \\
\hline
\end{tabular}

M, male; F, female; DCM, dilated cardiomyopathy; ASD, atrial septal defect; LVEDD, left ventricular end-diastolic diameter; LVESD, left ventricular end-systolic diameter; LVEF, left ventricular ejection fraction; PAF, paroxysmal atrial fibrillation; AVB, atrioventricular conduction block; RBBB, right bundle branch block; +, presence of mutation; -, absence of mutation.

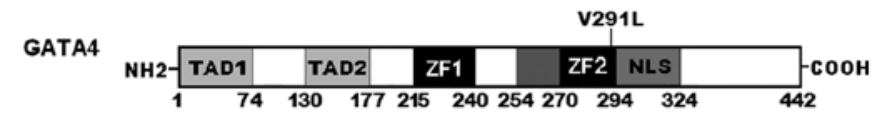

Figure 2. Schematic diagram of the GATA4 protein structure with the dilated cardiomyopathy-associated mutation indicated. The mutation identified in the patients with dilated cardiomyopathy is shown above the structural domains. NH2, amino-terminus; TAD, transcriptional activation domain; ZF, zinc finger; NLS, nuclear localization signal; $\mathrm{COOH}$, carboxyl-terminus.

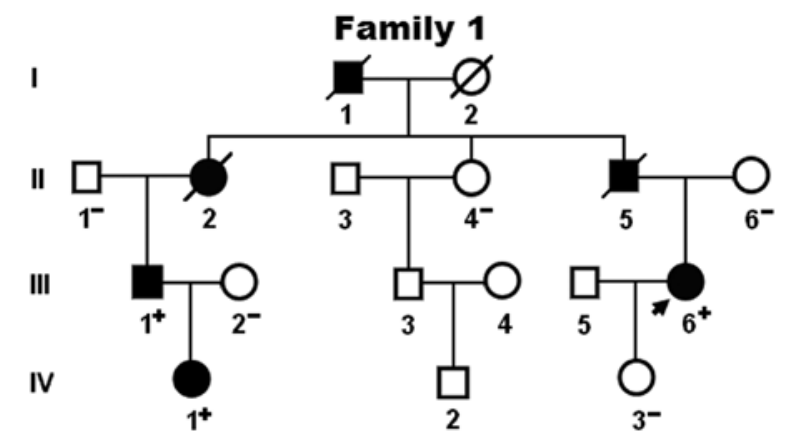

Figure 3. Pedigree structure of the family with dilated cardiomyopathy. Family members are identified by generations and numbers. Square, male family member; circle, female member; symbols with a slash, deceased members; closed symbols, affected members; open symbols, unaffected members; arrow, proband; +, carrier of the heterozygous missense mutation; -, non-carrier.

of valine (V) into leucine (L) at amino acid position 291 (p.V291L) was identified in the proband from family 1 . The sequence chromatograms showing the detected heterozygous GATA4 mutation of $\mathrm{c} .871 \mathrm{G}>\mathrm{C}$ compared with its control sequence are shown in Fig. 1. A schematic diagram of GATA4 protein depicting the structural domains and location of the mutation identified in this study is presented in Fig. 2. The missense mutation was neither observed in the control population nor reported in the SNP and HGM databases. The genetic scan of the family showed that the mutation was present in all affected living family members, but absent in the unaffected family members examined. Analysis of the pedigree demonstrated that the mutation co-segregated with DCM was transmitted in an autosomal dominant pattern in the family with complete penetrance. The pedigree structure of the family is illustrated in Fig. 3. The phenotypic characteristics and status of the GATA4 mutation of the affected living family members are listed in Table II.

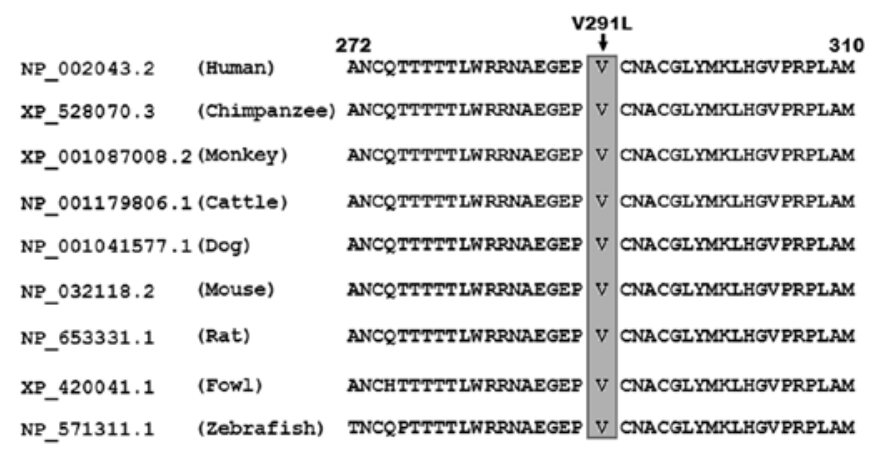

Figure 4. Multiple alignments of GATA4 protein sequences among species. The altered amino acid of p.V291 is completely conserved evolutionarily across species.

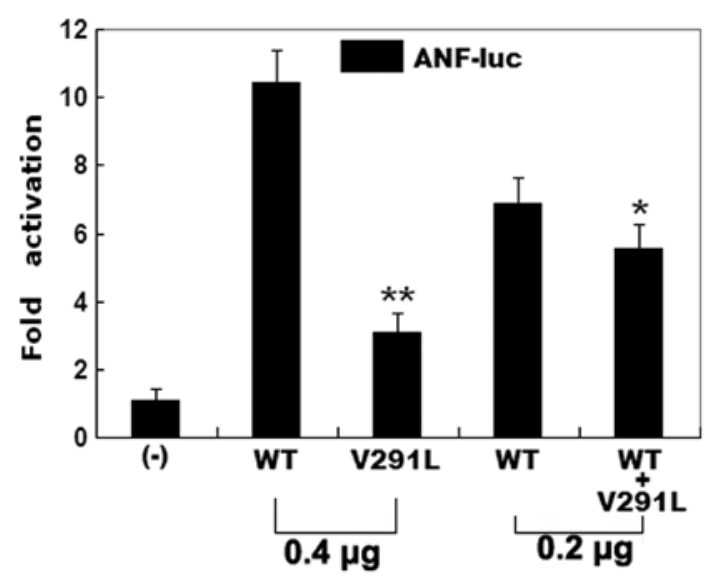

Figure 5. Functional impairment results from the GATA4 mutation. Activation of the atrial natriuretic factor promoter driven luciferase reporter in HeLa cells by wild-type (WT) or V291L-mutant GATA4, alone or together, showed significantly reduced transcriptional activation by the mutant protein. Experiments were performed in triplicate, and mean and standard deviations are shown. ${ }^{* *} \mathrm{P}<0.001$ and ${ }^{*} \mathrm{P}<0.005$, respectively, when compared with wildtype GATA4.

In addition, individual III-1 and his mother (II-2) also had documented congenital atrial septal defect and paroxysmal atrial fibrillation as well as first-degree atrioventricular conduction block and incomplete right bundle branch block.

Multiple alignments of GATA4 protein sequences. A crossspecies alignment of GATA4 protein sequences showed that 
the altered amino acid p.V291 was completely conserved evolutionarily (Fig. 4).

Disease-causing potential of the GATA4 variation. The GATA4 sequence variation of $c .871 \mathrm{G}>\mathrm{C}$ was predicted by MutationTaster to be a disease-causing mutation with a P-value of nearly 1.0. No SNPs in the altered region were found in the MutationTaster database. This GATA4 sequence variation was also predicted by PolyPhen-2 to be probably damaging, with a score of 0.997 (sensitivity 0.41 ; specificity 0.98 ).

Transcriptional activity of the GATA4 mutant. The same amount $(0.4 \mu \mathrm{g})$ of wild-type and mutant GATA4 activated the $A N F$ promoter by $\sim 10$ - and 3 -fold, respectively (Fig. 5). When the same amount of wild-type GATA4 $(0.2 \mu \mathrm{g})$ was co-transfected with mutant GATA4 $(0.2 \mu \mathrm{g})$, the induced activation of the $A N F$ promoter was $\sim 6$-fold. These results suggest that the GATA4 mutant has a significantly reduced activation activity compared with the wild-type counterpart.

\section{Discussion}

In the present study, a novel heterozygous GATA4 mutation of p.V291L was identified in a family with idiopathic DCM. The missense mutation co-segregated with DCM in the family and was absent in the 400 reference chromosomes from an ethnically matched control population. A cross-species alignment of multiple GATA4 protein sequences showed that the altered amino acid was completely conserved evolutionarily. Functional analysis revealed that the mutant was associated with significantly reduced transcriptional activity. Therefore, it is likely that GATA4 loss-of-function mutation predisposes these mutation carriers to DCM.

It has been verified that GATA4 is a transcriptional activator of several genes expressed during cardiac development, including the $A N F$ gene (7). Hence, the functional effect of the GATA4 mutation may be investigated by assaying the transcriptional activity of the $A N F$ promoter in cells expressing GATA4. In the present study, the functional role of the novel p.V291L mutation of GATA4 identified in the familial DCM patients was characterized by transcriptional activity analysis. The data showed significantly diminished transcriptional activity on a target gene. These results support that the haploinsufficiency or dominant-negative effect resulting from the GATA4 mutation is potentially an alternative pathological mechanism of DCM.

The findings that GATA4 loss-of-function mutation enhances the susceptibility to DCM may be partially ascribed to the developmental and regenerative defects of the myocardium as well as abnormal heart remodeling (17). During embryonic genesis, GATA4 is required for activation and maintenance of the core cardiac regulatory network, and GATA4-null mutations suppress myocardial specification and maturation, giving rise to death (35). GATA4 also plays a central role in the postnatal maturation and homeostasis of cardiomyocytes and adult heart function as well as adaptation (21). Mice with cardiomyocyte-restricted deletion of GATA4 were viable and survived into adulthood, but they underwent a progressive deterioration in cardiac function and enlargement of the heart in adulthood. Furthermore, in this mouse model, pressure overload or exercise stimulation failed to elicit cardiac hypertrophy, but induced rapid decompensation, precipitous heart failure and increased apoptosis (21). In contrast, overexpression of GATA4 in the heart was sufficient for inducing cardiac hypertrophy (36). In humans, mutations in GATA4 and its transcriptionally cooperative partners, including NKX2-2 and TBX20, have been associated with familial DCM $(17,33,37)$. Taken together, these findings provide evidence that the GATA4 mutation contributes to DCM.

In addition, transcriptions of a number of important cardiac genes are activated by GATA4, and mutations in multiple target molecules have been found to be responsible for DCM, including $\alpha$-actin, $\alpha$-myosin heavy chain, troponin $C$ and troponin I $(3,7)$. Therefore, functionally compromised GATA4 increases the vulnerability to DCM probably by reducing expression of target genes.

Similar with previous studies (8-16,38-40), in the present study, congenital heart disease and paroxysmal atrial fibrillation were observed in 2 patients harboring the GATA4 mutation. In addition, the other 2 members of the GATA family, GATA5 and GATA6 have similar expression profile and functional characteristics with GATA4 (5), and mutations in GATA5 and GATA6 are also involved in congenital heart disease and atrial fibrillation (41-56). These observational results underscore the critical role of GATA transcription factors in the development, remodeling and function of the heart.

In conclusion, the present study expands the mutational spectrum of GATA4 linked to DCM and provides novel insight into the molecular pathogenesis of DCM, suggesting potential implications in prenatal prophylaxis and personalized treatment of DCM.

\section{Acknowledgements}

We are thankful to the participants for their dedication to the study. The present study was supported by grants from the National Natural Science Fund of China (81070153, 81270161 and 81270314), and the National Basic Research Program of China (2010CB912604).

\section{References}

1. Garcia-Pavia P, Cobo-Marcos M, Guzzo-Merello G Gomez-Bueno M, Bornstein B, Lara-Pezzi E, Segovia J and Alonso-Pulpon L: Genetics in dilated cardiomyopathy. Biomark Med 7: 517-533, 2013.

2. Lakdawala NK, Winterfield JR and Funke BH: Dilated cardiomyopathy. Circ Arrhythm Electrophysiol 6: 228-237, 2013.

3. McNally EM, Golbus JR and Puckelwartz MJ: Genetic mutations and mechanisms in dilated cardiomyopathy. J Clin Invest 123: 19-26, 2013.

4. Flack E and Kannankeril PJ: The genetics of dilated cardiomyopathy. Heart Rhythm 9: 397-398, 2012.

5. Pikkarainen S, Tokola H, Kerkelä R and Ruskoaho H: GATA transcription factors in the developing and adult heart. Cardiovasc Res 63: 196-207, 2004.

6. Perrino C and Rockman HA: GATA4 and the two sides of gene expression reprogramming. Circ Res 98: 715-716, 2006.

7. Brody MJ, Cho E, Mysliwiec MR, Kim TG, Carlson CD, Lee KH and Lee Y: Lrrc10 is a novel cardiac-specific target gene of Nkx2-5 and GATA4. J Mol Cell Cardiol 62: 237-246, 2013.

8. Garg V, Kathiriya IS, Barnes R, Schluterman MK, King IN, Butler CA, Rothrock CR, Eapen RS, Hirayama-Yamada K, Joo K, Matsuoka R, Cohen JC and Srivastava D: GATA4 mutations cause human congenital heart defects and reveal an interaction with TBX5. Nature 424: 443-447, 2003. 
9. Rajagopal SK, Ma Q, Obler D, Shen J, Manichaikul A, TomitaMitchell A, Boardman K, Briggs C, Garg V, Srivastava D, Goldmuntz E, Broman KW, Benson DW, Smoot LB and Pu WT: Spectrum of heart disease associated with murine and human GATA4 mutation. J Mol Cell Cardiol 43: 677-685, 2007.

10. Wang J, Fang M, Liu XY, Xin YF, Liu ZM, Chen XZ, Wang XZ, Fang WY, Liu X and Yang YQ: A novel GATA4 mutation responsible for congenital ventricular septal defects. Int J Mol Med 28: 557-564, 2011

11. Liu XY, Wang J, Zheng JH, Bai K, Liu ZM, Wang XZ, Liu X, Fang WY and Yang YQ: Involvement of a novel GATA4 mutation in atrial septal defects. Int J Mol Med 28: 17-23, 2011.

12. McCulley DJ and Black BL: Transcription factor pathways and congenital heart disease. Curr Top Dev Biol 100: 253-277, 2012.

13. Yang YQ, Li L, Wang J, Liu XY, Chen XZ, Zhang W, Wang XZ, Jiang JQ, Liu X and Fang WY: A novel GATA4 loss-of-function mutation associated with congenital ventricular septal defect. Pediatr Cardiol 33: 539-546, 2012.

14. Yang YQ, Wang J, Liu XY, Chen XZ, Zhang W, Wang XZ, Liu X and Fang WY: Novel GATA4 mutations in patients with congenital ventricular septal defects. Med Sci Monit 18: CR344-CR350, 2012.

15. Wang E, Sun S, Qiao B, Duan W, Huang G, An Y, Xu S, Zheng Y $\mathrm{Su} \mathrm{Z}, \mathrm{Gu} \mathrm{X}$, Jin L and Wang H: Identification of functional mutations in GATA4 in patients with congenital heart disease. PLoS One 8: e62138, 2013.

16. Yang YQ, Gharibeh L, Li RG, Xin YF, Wang J, Liu ZM, Qiu XB Xu YJ, Xu L, Qu XK, Liu X, Fang WY, Huang RT, Xue S and Nemer G: GATA4 loss-of-function mutations underlie familial tetralogy of Fallot. Hum Mutat 34: 1662-1671, 2013.

17. Li RG, Li L, Qiu XB, Yuan F, Xu L, Li X, Xu YJ, Jiang WF, Jiang JQ, Liu X, Fang WY, Zhang M, Peng LY, Qu XK and Yang YQ: GATA4 loss-of-function mutation underlies familial dilated cardiomyopathy. Biochem Biophys Res Commun 439: 591-596, 2013

18. Molkentin JD, Lin Q, Duncan SA and Olson EN: Requirement of the transcription factor GATA4 for heart tube formation and ventral morphogenesis. Genes Dev 11: 1061-1072, 1997.

19. Kuo CT, Morrisey EE, Anandappa R, Sigrist K, Lu MM, Parmacek MS, Soudais C and Leiden JM: GATA4 transcription factor is required for ventral morphogenesis and heart tube formation. Genes Dev 11: 1048-1060, 1997.

20. Pu WT, Ishiwata T, Juraszek AL, Ma Q and Izumo S: GATA4 is a dosage-sensitive regulator of cardiac morphogenesis. Dev Biol 275: 235-244, 2004

21. Oka T, Maillet M, Watt AJ, Schwartz RJ, Aronow BJ, Duncan SA and Molkentin JD: Cardiac-specific deletion of Gata4 reveals its requirement for hypertrophy, compensation, and myocyte viability. Circ Res 98: 837-845, 2006.

22. Suzuki YJ and Evans TL: Regulation of cardiac myocyte apoptosis by the GATA-4 transcription factor. Life Sci 74 : $1829-1838,2004$

23. Xu X, Zhang L and Liang J: Rosuvastatin prevents pressure overload-induced myocardial hypertrophy via inactivation of the Akt, ERK1/2 and GATA4 signaling pathways in rats. Mol Med Rep 8: 385-392, 2013.

24. Kikuchi K, Holdway JE, Werdich AA, Anderson RM, Fang Y, Egnaczyk GF, Evans T, Macrae CA, Stainier DY and Poss KD: Primary contribution to zebrafish heart regeneration by gata4(+) cardiomyocytes. Nature 464: 601-605, 2010.

25. Qian L, Huang Y, Spencer CI, Foley A, Vedantham V, Liu L, Conway SJ, Fu JD and Srivastava D: In vivo reprogramming of murine cardiac fibroblasts into induced cardiomyocytes. Nature 485: 593-598, 2012.

26. Song K, Nam YJ, Luo X, Qi X, Tan W, Huang GN, Acharya A, Smith CL, Tallquist MD, Neilson EG, Hill JA, Bassel-Duby R and Olson EN: Heart repair by reprogramming non-myocytes with cardiac transcription factors. Nature 485: 599-604, 2012.

27. Lyons I, Parsons LM, Hartley L, Li R, Andrews JE, Robb L and Harvey RP: Myogenic and morphogenetic defects in the heart tubes of murine embryos lacking the homeo box gene Nkx2-5. Genes Dev 9: 1654-1666, 1995.

28. Prall OW, Menon MK, Solloway MJ, Watanabe Y, Zaffran S, Bajolle F, Biben C, McBride JJ, Robertson BR, Chaulet H, Stennard FA, Wise N, Schaft D, Wolstein O, Furtado MB, Shiratori H, Chien KR, Hamada H, Black BL, Saga Y, Robertson EJ, Buckingham ME and Harvey RP: An Nkx2-5/ Bmp2/Smad1 negative feedback loop controls heart progenitor specification and proliferation. Cell 128: 947-959, 2007.
29. Pashmforoush M, Lu JT, Chen H, Amand TS, Kondo R, Pradervand S, Evans SM, Clark B, Feramisco JR, Giles W, Ho SY, Benson DW, Silberbach M, Shou W and Chien KR: Nkx2-5 pathways and congenital heart disease; loss of ventricular myocyte lineage specification leads to progressive cardiomyopathy and complete heart block. Cell 117: 373-386, 2004.

30. Schott JJ, Benson DW, Basson CT, Pease W, Silberbach GM, Moak JP, Maron BJ, Seidman CE and Seidman JG: Congenital heart disease caused by mutations in the transcription factor NKX2-5. Science 281: 108-111, 1998.

31. Reamon-Buettner SM and Borlak J: NKX2-5: an update on this hypermutable homeodomain protein and its role in human congenital heart disease (CHD). Hum Mutat 31: 1185-1194, 2010.

32. Wang J, Xin YF, Liu XY, Liu ZM, Wang XZ and Yang YQ: A novel NKX2-5 mutation in familial ventricular septal defect. Int J Mol Med 27: 369-375, 2011

33. Costa MW, Guo G, Wolstein O, Vale M, Castro ML, Wang L, Otway R, Riek P, Cochrane N, Furtado M, Semsarian C, Weintraub RG, Yeoh T, Hayward C, Keogh A, Macdonald P, Feneley M, Graham RM, Seidman JG, Seidman CE, Rosenthal N, Fatkin D and Harvey RP: Functional characterization of a novel mutation in NKX2-5 associated with congenital heart disease and adult-onset cardiomyopathy. Circ Cardiovasc Genet 6: 238-247, 2013.

34. Elliott P, O'Mahony C, Syrris P, Evans A, Rivera Sorensen C, Sheppard MN, Carr-White G, Pantazis A and McKenna WJ: Prevalence of desmosomal protein gene mutations in patients with dilated cardiomyopathy. Circ Cardiovasc Genet 3: 314-322, 2010.

35. Schlesinger J, Schueler M, Grunert M, Fischer JJ, Zhang Q, Krueger T, Lange M, Tönjes M, Dunkel I and Sperling SR: The cardiac transcription network modulated by Gata4, Mef2a, Nkx2.5, Srf, histone modifications, and microRNAs. PLoS Genet 7: e1001313, 2011.

36. Liang Q, De Windt LJ, Witt SA, Kimball TR, Markham BE and Molkentin JD: The transcription factors GATA4 and GATA6 regulate cardiomyocyte hypertrophy in vitro and in vivo. J Biol Chem 276: 30245-30253, 2001.

37. Kirk EP, Sunde M, Costa MW, Rankin SA, Wolstein O, Castro ML, Butler TL, Hyun C, Guo G, Otway R, Mackay JP, Waddell LB, Cole AD, Hayward C, Keogh A, Macdonald P, Griffiths L, Fatkin D, Sholler GF, Zorn AM, Feneley MP, Winlaw DS and Harvey RP: Mutations in cardiac T-box factor gene TBX20 are associated with diverse cardiac pathologies, including defects of septation and valvulogenesis and cardiomyopathy. Am J Hum Genet 81: 280-291, 2007.

38. Jiang JQ, Shen FF, Fang WY, Liu X and Yang YQ: Novel GATA4 mutations in lone atrial fibrillation. Int J Mol Med 28: 1025-1032, 2011.

39. Yang YQ, Wang MY, Zhang XL, Tan HW, Shi HF, Jiang WF, Wang XH, Fang WY and Liu X: GATA4 loss-of-function mutations in familial atrial fibrillation. Clin Chim Acta 412: 1825-1830, 2011.

40. Wang J, Sun YM and Yang YQ: Mutation spectrum of the GATA4 gene in patients with idiopathic atrial fibrillation. Mol Biol Rep 39: 8127-8135, 2012.

41. Jiang JQ, Li RG, Wang J, Liu XY, Xu YJ, Fang WY, Chen XZ Zhang W, Wang XZ and Yang YQ: Prevalence and spectrum of GATA 5 mutations associated with congenital heart disease. Int J Cardiol 165: 570-573, 2013

42. Wei D, Bao H, Liu XY, Zhou N, Wang Q, Li RG, Xu YJ and Yang YQ: GATA5 loss-of-function mutations underlie tetralogy of Fallot. Int J Med Sci 10: 34-42, 2013.

43. Wei D, Bao H, Zhou N, Zheng GF, Liu XY and Yang YQ: GATA5 loss-of-function mutation responsible for the congenital ventriculoseptal defect. Pediatr Cardiol 34: 504-511, 2013.

44. Yang YQ, Wang J, Wang XH, Wang Q, Tan HW, Zhang M, Shen FF, Jiang JQ, Fang WY and Liu X: Mutational spectrum of the GATA5 gene associated with familial atrial fibrillation. Int J Cardiol 157: 305-307, 2012.

45. Gu JY, Xu JH, Yu H and Yang YQ: Novel GATA5 loss-offunction mutations underlie familial atrial fibrillation. Clinics (Sao Paulo) 67: 1393-1399, 2012.

46. Wang XH, Huang CX, Wang Q, Li RG, Xu YJ, Liu X, Fang WY and Yang YQ: A novel GATA5 loss-of-function mutation underlies lone atrial fibrillation. Int J Mol Med 31: 43-50, 2013 
47. Kodo K, Nishizawa T, Furutani M, Arai S, Yamamura E, Joo K, Takahashi T, Matsuoka R and Yamagishi H: GATA6 mutations cause human cardiac outflow tract defects by disrupting semaphorin-plexin signaling. Proc Natl Acad Sci USA 106: 13933-13938, 2009.

48. Maitra M, Koenig SN, Srivastava D and Garg V: Identification of GATA6 sequence variants in patients with congenital heart defects. Pediatr Res 68: 281-285, 2010.

49. Lin X, Huo Z, Liu X, Zhang Y, Li L, Zhao H, Yan B, Liu Y, Yang Y and Chen YH: A novel GATA6 mutation in patients with tetralogy of Fallot or atrial septal defect. J Hum Genet 55: 662-667, 2010.

50. Wang J, Luo XJ, Xin YF, Liu Y, Liu ZM, Wang Q, Li RG, Fang WY, Wang XZ and Yang YQ: Novel GATA6 mutations associated with congenital ventricular septal defect or tetralogy of Fallot. DNA Cell Biol 31: 1610-1617, 2012.

51. Zheng GF, Wei D, Zhao H, Zhou N, Yang YQ and Liu XY: A novel GATA6 mutation associated with congenital ventricular septal defect. Int J Mol Med 29: 1065-1071, 2012.
52. Huang RT, Xue S, Xu YJ and Yang YQ: Somatic mutations in the GATA6 gene underlie sporadic tetralogy of Fallot. Int J Mol Med 31: 51-58, 2013

53. Bui PH, Dorrani N, Wong D, Perens G, Dipple KM and QuinteroRivera F: First report of a de novo 18q11.2 microdeletion including GATA6 associated with complex congenital heart disease and renal abnormalities. Am J Med Genet A 161A: 1773-1778, 2013.

54. Yang YQ, Wang XH, Tan HW, Jiang WF, Fang WY and Liu X: Prevalence and spectrum of GATA6 mutations associated with familial atrial fibrillation. Int J Cardiol 155: 494-496, 2012.

55. Yang YQ, Li L, Wang J, Zhang XL, Li RG, Xu YJ, Tan HW, Wang XH, Jiang JQ, Fang WY and Liu X: GATA6 loss-offunction mutation in atrial fibrillation. Eur J Med Genet 55: 520-526, 2012

56. Li J, Liu WD, Yang ZL and Yang YQ: Novel GATA6 loss-offunction mutation responsible for familial atrial fibrillation. Int J Mol Med 30: 783-790, 2012. 